\title{
Apoptosome dysfunction in human cancer
}

\author{
K. M. Hajra and J. R. Liu \\ Department of Obstetrics and Gynecology, University of Michigan Medical School, L4000 Women's Hospital, \\ 1500 East Medical Center Drive, Ann Arbor, MI 48109, USA
}

\begin{abstract}
Apoptosis is a cell suicide mechanism that enables organisms to control cell number and eliminate cells that threaten survival. The apoptotic cascade can be triggered through two major pathways. Extracellular signals such as members of the tumor necrosis factor (TNF) family can activate the receptor-mediated extrinsic pathway. Alternatively, stress signals such as DNA damage, hypoxia, and loss of survival signals may trigger the mitochondrial intrinsic pathway. In the latter, mitochondrial damage results in cytochrome $c$ release and formation of the apoptosome, a multimeric protein complex containing Apaf-1, cytochrome $c$, and caspase-9. Once bound to the apoptosome, caspase-9 is activated, and subsequently triggers a cascade of effector caspase activation and proteolysis, leading to apoptotic cell death. Recent efforts have led to the identification of multiple factors that modulate apoptosome formation and function. Alterations in the expression and/or function of these factors may contribute to the pathogenesis of cancer and resistance of tumor cells to chemotherapy or radiation. In this review we discuss how disruption of normal apoptosome formation and function may lead or contribute to tumor development and progression.
\end{abstract}

\section{Keywords: Apaf-1; apoptosis; apoptosome; Bcl-2; IAP.}

Abbreviations: AlF-apoptosis inducing factor; Apaf-1apoptotic protease-activating factor-1; $\mathrm{BH}-\mathrm{Bcl}-2$ homology domain; BIR-baculoviral IAP repeat; CARD—caspase recruitment domain; DIABLO-direct IAP-binding protein with low pl; ER-endoplasmic reticulum; FADD-fasassociated protein with a death domain; HSP-heat shock protein; HtrA2-high temperature requirement $\mathrm{A} 2$; IAP-inhibitor of apoptosis; PHAP-putative HLA-DRassociated proteins; PARP—poly(ADP)-ribose polymerase; PI3K-phosphatidylinositol 3-kinase; ProT-Prothymosin- $\alpha$; Smac-second mitochondria-derived activator of caspases; TNF-tumor necrosis factor; TRAMP-TNFR-related apoptosis-mediating protein; TRAIL-TNF-related apoptosisinducing ligand; UV-ultraviolet; XIAP-x-linked inhibitor of apoptosis.

Correspondence to: J. Rebecca Liu, M.D., Department of Obstetrics and Gynecology, University of Michigan Medical School, L4000 Women's Hospital, 1500 East Medical Center Drive, Ann Arbor, MI 48109, USA. Tel.: 734-615-3773; Fax: 734764-7261; e-mail: rliu@umich.edu

\section{Introduction}

The major apoptosis pathways

Apoptosis is an evolutionarily conserved, genetically controlled process of programmed cell death, used by multicellular organisms to eliminate cells in diverse physiological settings, such as development, homeostasis of tissues, and maintenance of integrity of the organism. ${ }^{1,2}$ Intense work over the past several years has lead to the identification of molecules involved in the control and implementation of cell death. Disruption of the normal apoptotic machinery contributes to a number of human disorders, including cancer, immunodeficient and autoimmune states, and neurodegenerative diseases. Thus, understanding the molecular mechanism and regulation of normal apoptotic function is important for understanding these disease states and how they might be best treated.

Two major pathways leading to apoptosis have been delineated: the extrinsic or receptor-mediated pathway, and the intrinsic or mitochondrial pathway (Figure 1). ${ }^{3}$ Both pathways involve the activation of a cascade of enzymes called caspases, a family of cysteine proteases that cleave after aspartic acid residues. Caspases are initially synthesized as zymogens, and during activation they are processed at a caspase cleavage site to generate their active forms. The extrinsic and intrinsic pathways have an independent group of "initiator" caspases, and the pathways converge to utilize the same group of "effector" caspases that execute the final cell death program.

The extrinsic or receptor-mediated pathway is characterized by the activation of cell surface death receptors following binding of their specific ligand (Figure 1). These death receptors belong to the tumor necrosis factor/nerve growth factor receptor superfamily, and include such members as Fas, TNFR1, TRAMP, and the TRAIL receptors. ${ }^{4}$ These receptors are characterized by a cysteinerich repeat in their extracellular domain and a conserved cytoplasmic sequence called the death domain. Ligand binding to the extracellular domain of the death receptor results in receptor trimerization, with the subsequent recruitment of the adaptor molecule FADD to the death 
Figure 1. The extrinsic and intrinsic pathways of apoptosis. The extrinsic pathway is triggered following ligand binding to receptors of the tumor necrosis factor (TNF) superfamily, leading to receptor multimerization. The adaptor molecule FADD then binds to the cytoplasmic domain of the receptor, and initiator caspases bind to the death effector domain of FADD. Initiator caspases undergo autocatalytic processing resulting in subsequent activation of effector caspases, including caspase-3, -6 , and -7 . The intrinsic pathway of apoptosis is triggered following mitochondrial damage, which leads to cytochrome $c$ release. There is subsequent formation of the apoptosome, a multiprotein complex containing cytochrome $c$, Apaf-1, and caspase-9. Following caspase- 9 activation, the intrinsic pathway converges with the extrinsic pathway at the level of effector caspase activation, and these effector caspases carry out the apoptotic cell death program.

\section{EXTRINSIC PATHWAY}

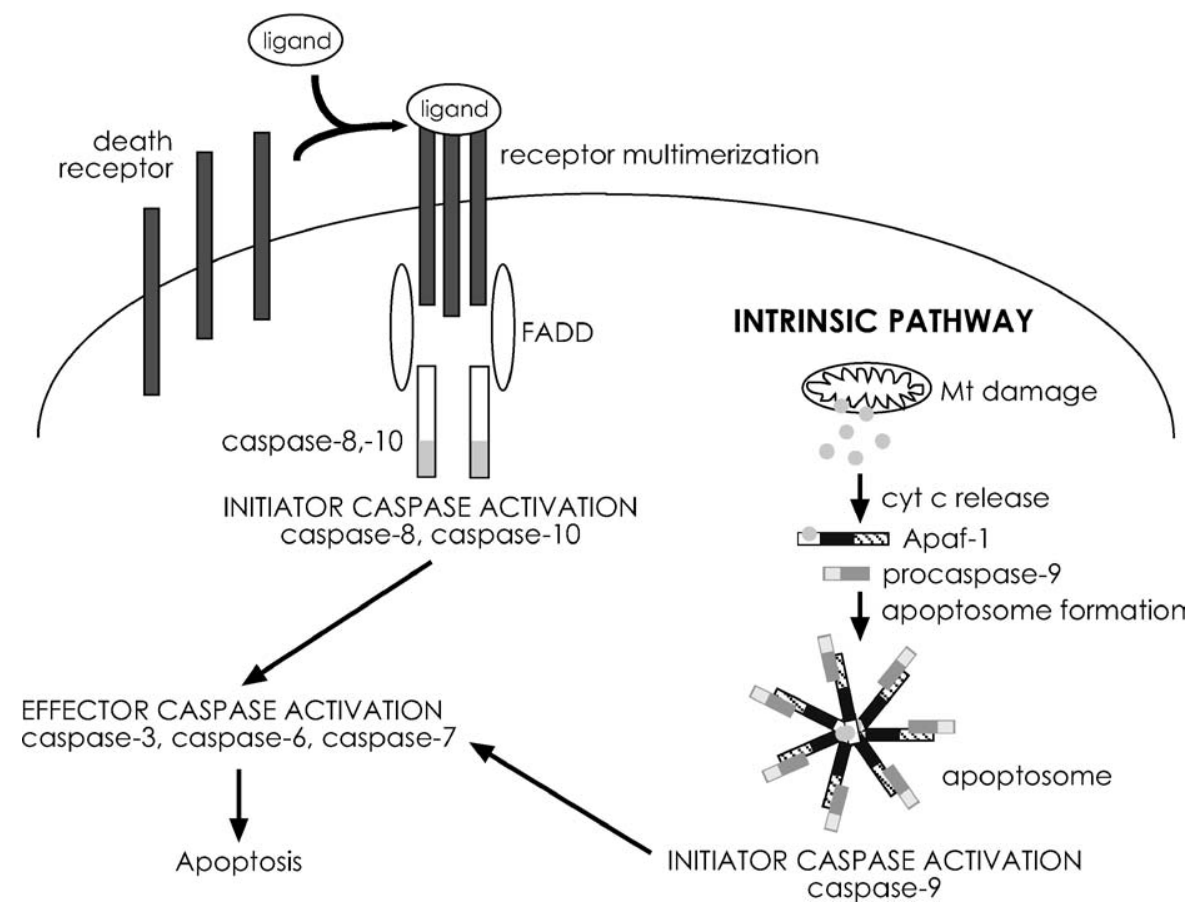

domain on the cytoplasmic face of the receptor. This adaptor molecule is able to recruit initiator procaspase- 8 and/or procaspase-10. Following recruitment, the high local concentration of the procaspase molecules promotes autocatalysis to their active forms. These activated initiator caspases are then able to carry out the downstream proteolytic processing of the effector caspases-3, -6, and -7, which execute the cell death program.

The intrinsic or mitochondrial pathway can be executed independent of death receptor signaling, and also results in the activation of effector caspases (Figure 1). The essential components of this pathway were identified through a biochemical approach in a cell-free system. In a now well-characterized process, mitochondrial damage results in the leakage of cytochrome $c$ into the cytoplasm. Subsequently, cytochrome $c$ complexes with the cytoplasmic protein Apaf-1, which then oligomerizes and binds to procaspase-9, resulting in the formation of a multimeric complex called the apoptosome. This brings procaspase- 9 molecules into close proximity with each other, allowing enzymatic self-activation. Caspase-9 is then is able to cleave and activate the downstream effector caspases- 3 , -6 , and $-7 . .^{5-7}$
Since the original identification of Apaf- $1,{ }^{7}$ its structure and function in the apoptosome have been further characterized. The primary structure of Apaf-1 consists of an amino-terminus with 12 or 13 WD-40 repeats, a central ATPase domain with homology to CED-4, and a carboxy-terminal caspase recruitment domain (CARD). There are four major isoforms of the protein that are defined by the presence or absence of two sequences, an 11 amino acid insert between the ATPase domain and CARD, and an additional WD-40 repeat between repeats 5 and $6 .{ }^{8}$ Studies have shown that this additional WD40 repeat, and thus a total of 13 repeats, is necessary for caspase- 9 activation in response to cytochrome $c$ and dATP. ${ }^{8}$ Analysis of the three-dimensional crystal structure of the apoptosome has revealed a model in which cytochrome $c$ binds to the WD-40 repeat region, and dATP binds to the ATPase domain of Apaf- 1 . This results in a conformational change in Apaf-1, and the formation of a wheel-like apoptosome structure containing seven Apaf-1 molecules. ${ }^{9}$ In the apoptosome complex, Apaf- 1 interacts with the adjacent Apaf-1 molecules via their $\mathrm{N}$-terminal CARD domains to form a central hub region, and the $\mathrm{C}$ terminal WD40 repeats are extended to form the outside 
ring. ${ }^{10}$ Each Apaf-1 molecule is bound to procaspase-9 via a CARD-CARD interaction. ${ }^{9}$ It appears that the WD-40 repeat region of Apaf-1 functions to inhibit apoptosome formation, as the deletion of the WD-40 region results in constitutively active Apaf- 1 that facilitates caspase- 9 activation in the absence of cytochrome $c .{ }^{11}$ Additionally, a number of modulators of apoptosome formation and function have been described and will be discussed in further detail below.

Unlike initiator caspases that are activated through an autocatalytic process, effector caspases such as caspase- 3 , -6 , and -7 are cleaved by another caspase that enzymatically removes the short prodomain of the effector caspase. Once activated, the effector caspases degrade vital cellular proteins, leading to cell death. Specific substrates of these caspases include structural proteins such as actin and nuclear lamin, regulatory proteins such as DNA-dependent protein kinase, and inhibitors of deoxyribonuclease. ${ }^{12}$ The cellular proteolysis carried out by effector caspases results in the biochemical and morphological cellular changes characteristic of apoptosis, including nuclear membrane breakdown, DNA fragmentation, chromatin condensation, and the formation of apoptotic bodies. ${ }^{13}$

Recent data suggests that the two pathway model of apoptosis is oversimplified, and that there is cross-talk between the extrinsic and intrinsic pathways of apoptosis. The extrinsic pathway initiator caspase, caspase8 , has been shown to cleave the $\mathrm{BH} 3$-only protein $\mathrm{Bid}$, which then mediates mitochondrial membrane permeabilization and cytochrome $c$ release. ${ }^{14}$ This mechanism leads to mitochondrial amplification of the extrinsic pathway signal. Other studies have suggested that there is caspase activation prior to disruption of mitochondrial membrane integrity. For example, cytotoxic stress activates caspase-2, leading to translocation of the proapoptotic protein Bax to the mitochondria and subsequent cytochrome $c$ release. ${ }^{15}$ Through inhibition of caspase- 2 activation, investigators demonstrated that in their experimental system, caspase- 2 is necessary for mitochondriamediated apoptosis. ${ }^{15} \mathrm{~A}$ role for caspase-2 activation upstream of mitochondrial disruption has also been supported by additional studies. ${ }^{16}$ This data suggests that there is caspase activation prior to mitochondrial permeabilization. Finally, recent studies suggest that caspase9 activation can occur independent of the apoptosome. In one such study, TNF-receptor-induced apoptosis includes activation of caspase- 9 even in the absence of Apaf-1. ${ }^{17}$

Cellular homeostasis is the result of maintaining a delicate balance between cell growth and death. The inability of cells to undergo apoptosis in response to specific cues can lead to overgrowth and the development of malignancy. Thus, specific defects in the normal apoptotic pathways described above can result in tumorigenesis, and a number of recent reports suggest that apoptosome defects may contribute to the development of human cancers. Therapeutic modalities for cancer, e.g., chemotherapy and radiation therapy, induce cell death through activation of the mitochondrial pathway of apoptosis. Therefore, tumor resistance to therapy may result from alterations to the normal pathway of apoptosome-initiated cell death. A number of endogenous modulators of apoptosome function have been identified and serve as potential sites at which defects in the cell death program develop. In this review we will summarize the current understanding of the modulation of apoptosome formation and function, and address how these mechanisms may be altered in human cancers to promote both tumorigenesis and tumor resistance to standard therapies.

\section{Modulation of apoptosome formation and function}

\section{Inhibition of cytochrome $c$ release}

Since the intrinsic, mitochondrial pathway of apoptosis was first described, a number of factors that regulate apoptosome formation and execution of downstream signals have been identified (Figure 2). As discussed above, the initial step in activation of the intrinsic pathway for apoptosis is the release of cytochrome $c$ from the mitochondria. $\mathrm{Bcl}-2$ proteins have been described as guardians of mitochondrial cytochrome $c$ release. Bcl-2-related proteins can be divided into two groups: the anti-apoptotic $\mathrm{Bcl}-2$ family and the pro-apoptotic Bax and $\mathrm{BH} 3$-only proteins. ${ }^{18}$ Interactions between $\mathrm{Bcl}-2$ family members with opposing effects establish a balance between anti-apoptotic and pro-apoptotic cellular signals.

Bcl-2 family members, including $\mathrm{Bcl}-2$ and $\mathrm{Bcl}-\mathrm{x}_{\mathrm{L}}$, contain at least one $\mathrm{Bcl}-2$ homology domain $(\mathrm{BH})$, and are localized to the cytoplasmic face of the outer mitochondrial membrane, the endoplasmic reticulum, and the nucleus. Current data suggest that in mammalian cells, these proteins function in the maintenance of membrane integrity. Pro-survival Bcl-2 family members prevent cytochrome $c$ release from mitochondria, thus blocking the downstream intrinsic pathway events of apoptosome formation and caspase activation. ${ }^{18}$ This function for $\mathrm{Bcl}-2$ is supported by the findings that it is an integral membrane protein $^{19}$ and is able to prevent cytochrome $c$ release. ${ }^{20,21}$ In contrast, in C. elegans, Bcl-2 homologs bind the Apaf-1 homolog CED-4 to sequester it and prevent apoptosome formation until pro-apoptotic signals are received. Studies have shown that Bcl-2 and Apaf-1 do not bind in mammalian cells, ${ }^{22}$ supporting a membrane integrity model rather than a sequestration model for Bcl-2 function.

These anti-apoptotic effects of $\mathrm{Bcl}-2$ proteins are countered by the actions of the pro-apoptotic actions of Bax 
Figure 2. Apoptosome formation and its regulation. The formation of the apoptosome is a multistep process following mitochondrial damage. The major steps are shown in the figure, with key regulators for each step indicated. See the text for a thorough discussion of the regulation of apoptosome formation at each of these steps.

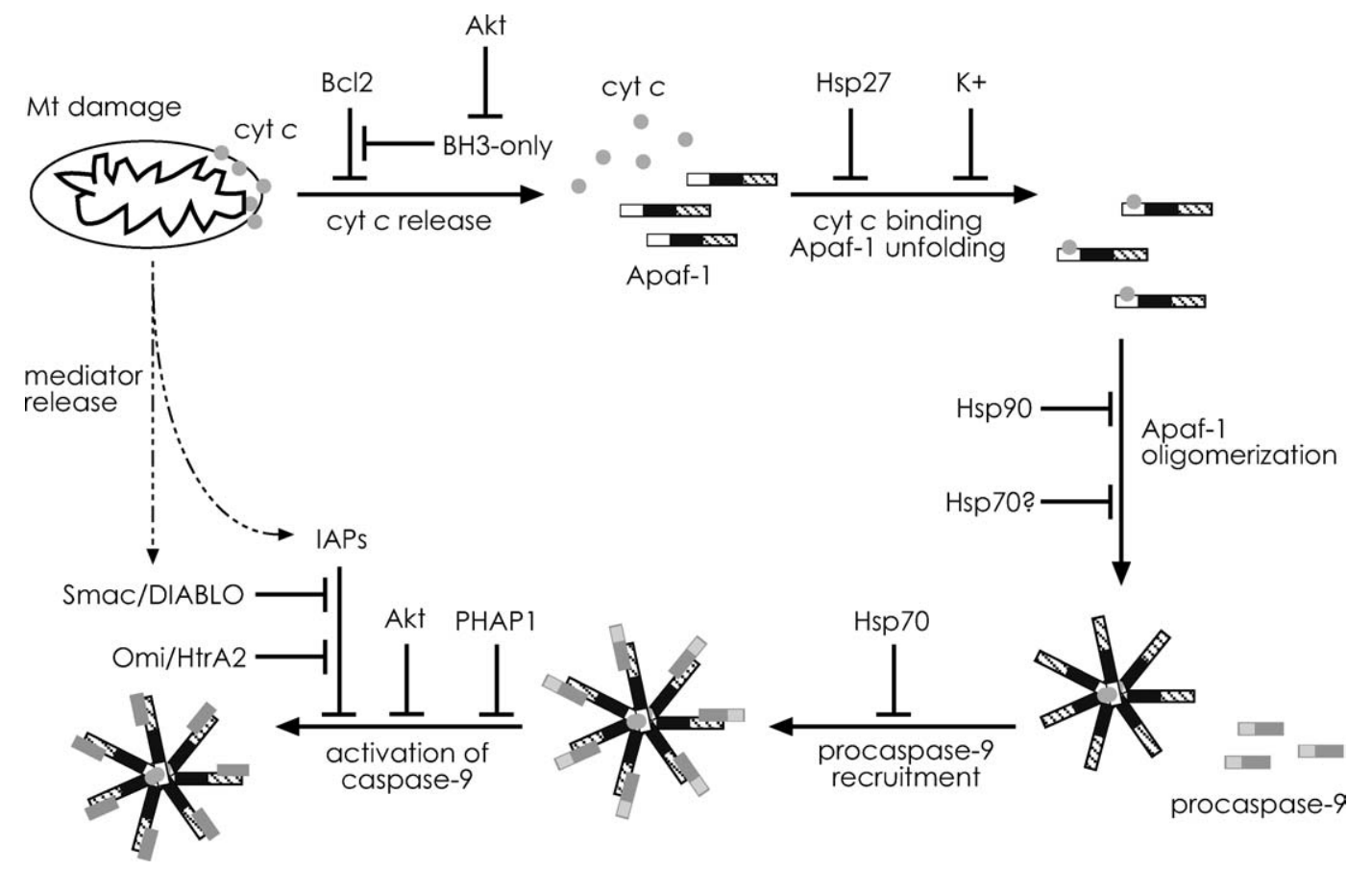

functional apoptosome

and $\mathrm{BH} 3$-only proteins. The physiologic role of these proteins is to sensitize cells to apoptosis. Mitochondrial membrane integrity is disrupted when $\mathrm{BH}$ 3-only proteins, such as Bim, Bik, and Bad, bind to and neutralize the antiapoptotic Bcl-2 proteins. Subsequently, pro-apoptotic Bax subfamily members, including Bax and Bak, form homooligomers in the mitochondrial membrane, thus altering membrane permeabilization and allowing cytochrome $c$ efflux. ${ }^{23}$ In support of this model, Bax family members are able to form pores in liposomes, resulting in cytochrome $c$ transport. $^{24-26}$ Once cytochrome $c$ is released from the mitochondria to the cytoplasm, it binds Apaf-1. Apaf1 then undergoes a conformational change as described above with resultant apoptosome formation and caspase activation.

The presence of at least twenty mammalian Bcl-2 family members speaks to the intricacy of apoptosis regulation in mammals. Numerous studies have illustrated the need for both the pro-apoptotic and anti-apoptotic Bcl2 -related proteins. For example, the importance of proapoptotic Bax proteins has been demonstrated through studies finding that $\mathrm{BH} 3$-only proteins are unable to kill cells in the absence Bax and $\mathrm{Bak}^{27,28}$ and mouse knockout studies have demonstrated that either Bax or Bak is required for stress-induced apoptosis. ${ }^{29}$

There are multiple mechanisms of regulation of Bcl2 family members, including the $\mathrm{Bax}$ and $\mathrm{BH} 3$-only subfamilies. ${ }^{18}$ One such mechanism of regulation is the phosphorylation of the pro-apoptotic protein Bad by the serine-threonine kinase Akt, thus inhibiting Bad's function. ${ }^{30,31}$ The ability of Akt to phosphorylate Bad and block its pro-apoptotic function is consistent with the pro-survival signals mediated by the phosphatidylinositol 3-kinase (PI3K) pathway that signals through the target protein Akt. Another important link between cellular metabolism and the apoptotic pathway has recently been elucidated. Pro-apoptotic Bad has been shown to complex with glucokinase, the first enzymatic step of multiple glucose metabolism pathways. ${ }^{32}$ Glucose deprivation of cells causes dephosphorylation of Bad and Bad-dependent apoptosis. ${ }^{32}$ This work establishes an important new link between glucose homeostasis and apoptosis.

Cytochrome $c$ may be inhibited following release from the mitochondria, thus preventing apoptosome formation and apoptosis. One study investigating the mechanism of UV-induced apoptosis in MCF-7 breast cancer cells demonstrates release of mitochondrial cytochrome $c$ followed by effector caspase-mediated apoptosis (cleavage of PARP) in the absence of caspase- 9 cleavage. ${ }^{33}$ In response to UV stimuli or treatment with valinomycin, mitochondrial cytochrome $c$ was released, however, pro-caspase-9 was not cleaved in MCF-7 cells unless exess exogenous cytochrome $c$ was added. The authors postulate the presence of a novel cytoplasmic inhibitor of cytochrome $c^{33}$; however, additional studies are needed to identify and characterize such a potential inhibitor. 


\section{Inhibition of apoptosome formation}

Following cytochrome $c$ release, the next step in the intrinsic pathway of apoptosis is the formation of the apoptosome. There are multiple factors that regulate this stage of the pathway (Figure 2). Heat shock proteins (HSPs) are a family of highly conserved proteins that are induced in response to a variety of cellular stresses and function to protect the cell. These proteins have been found to inhibit apoptosome formation in a number of reports, thus serving to suppress apoptosis in response to physiological and environmental stresses. ${ }^{34} \mathrm{Hsp} 70$ is a central protein in the cellular stress response system. Hsp70 has been shown to bind to the CARD domain of Apaf-1, with the resultant inhibition of apoptosome formation including an inability to recruit procaspase-9 to the complex. ${ }^{35,36}$ Different reports have disputed whether Apaf- 1 oligomerization is able to proceed in the presence of Hsp70. ${ }^{35,36}$ Interestingly, studies suggest that Hsp70 also functions to inhibit apoptosis independently of its effect on apoptosome formation. In Apaf- $1^{-/-}$mouse embryo fibroblasts, Hsp70 overexpression protects the cells from apoptosis following serum withdrawal. ${ }^{37}$ Hsp70 carries out this function by binding to apoptosis-inducing factor (AIF), a mitochondrial intermembrane flavoprotein that, upon release into the cytoplasm, translocates to the nucleus and induces caspase-independent apoptosis. ${ }^{38}$ Both Hsp90 and Hsp27 have also been shown to inhibit apoptosome formation. Hsp90 binds to Apaf-1 and inhibits Apaf-1 oligomerization and apoptosome formation in response to cellular stresses. ${ }^{39}$ Studies suggest that Hsp27 inhibits apoptosome formation by binding to and sequestering both cytochrome $c$ and procaspase- $3 .{ }^{40,41}$

The modulation of apoptosome formation is a balance between pro-apoptotic and anti-apoptotic signals. It has been shown in in vitro experiments that apoptosis is regulated by intracellular potassium ion $\left(\mathrm{K}^{+}\right)$levels, ${ }^{42,43}$ with physiological intracellular $\mathrm{K}^{+}$concentrations functioning to inhibit apoptosome formation by preventing Apaf- 1 oligomerization. ${ }^{43}$ This inhibition is overcome by increasing cytoplasmic concentrations of cytochrome $c$, and it is proposed that the mechanism for $\mathrm{K}^{+}$inhibition is through competition for cytochrome $c$ binding sites on Apaf-1. ${ }^{43}$ This inhibition of apoptosome formation by physiologic concentrations of $\mathrm{K}^{+}$may serve as a safety mechanism against initiation of the apoptotic cascade following the leakage of small amounts of cytochrome $c$ from the mitochondria.

Finally, recent work has demonstrated that the oncoprotein prothymosin- $\alpha$ (ProT) inhibits apoptosome formation, ${ }^{44}$ suggesting that one mechanism by which the protein is oncogenic is through the inhibition of apoptosis. Pro-T has been described as a transforming oncoprotein in vitro, and is associated with some human cancers. ${ }^{45,46}$ The precise molecular interactions by which ProT neg- atively regulates apoptosome formation have yet to be determined.

\section{Modulation of caspase activation}

The intrinsic pathway of apoptosis is also regulated by through the modulation of caspase activation by multiple proteins downstream of apoptosome formation (Figure 2). The inhibitor of apoptosis (IAP) proteins were initially identified in baculoviruses on the basis of their ability to suppress cell death in response to viral infection. To date over half a dozen human IAP proteins have been identified, including XIAP, cIAP1, cIAP2, NIAP, BRUCE, ML-IAP and Survivin. These proteins all contain at least one baculoviral IAP repeat (BIR) approximately 70 amino acids in length that is required for their ability to inhibit apoptosis. BIR domains 1 and 2 of IAPs bind and inhibit caspase -3 and -7 , whereas the BIR 3 domain binds to and specifically inhibits caspase- $9 .{ }^{47-49}$ Overexpression of human IAPs has been shown to suppress apoptosis in response to a number of stimuli, including those which activate the intrinsic pathway of apoptosis. ${ }^{49}$ IAP proteins appear to suppress apoptosis by directly inhibiting specific caspases. The IAP proteins XIAP, cIAP1, cIAP2 can bind to procaspase- 9 to prevent its processing and activation. ${ }^{47}$ Additionally, IAP proteins function to block the apoptotic cascade further downstream by binding to and inhibiting effector caspases including caspase- 3 and caspase-7. ${ }^{47,50,51}$

While the IAPs function to inhibit caspase activation, mammalian cells contain multiple proteins that function to remove this inhibition and promote apoptosis. Smac and its murine homolog DIABLO are normally localized to the mitochondrial intermembrane space, and are released into the cytosol in response to mitochondrial damage. Once in the cytosol, the pro-apoptotic protein Smac/DIABLO interacts with IAP family members to remove their inhibition of caspases. ${ }^{52,53} \mathrm{HtrA} 2 / \mathrm{Omi}$ is another protein that functions to relieve IAP inhibition of caspases. ${ }^{54-58} \mathrm{HtrA} 2 / \mathrm{Omi}$ is also released from the mitochondrial intermembrane space in response to mitochondrial damage, allowing it to interact with IAPs in the cytosol. Unlike Smac/DIABLO, HtrA2/Omi not only is able to bind to and inhibit IAPs, but it also has serine protease activity that facilitates cell death. ${ }^{55,58,59}$ The structural and biochemical basis of the interaction between these proteins and the IAPs has been reviewed elsewhere. $^{12}$

As discussed above, the serine-threonine kinase Akt mediates survival by phosphorylating and inactivating the pro-apoptotic protein Bad. In effecting its pro-survival signal, Akt also modulates caspase activation. Akt phosphorylation of procaspase-9 blocks cleavage of procaspase9 and subsequent activation of procaspase- $3 .{ }^{60}$ Taken 
together, these data demonstrate that Akt has multiple targets, the phosphorylation of all of which promotes cell survival by inhibiting the intrinsic pathway of apoptosis. These findings are consistent with the pro-survival effects of the growth factor signaling pathways through $\mathrm{PI} 3 \mathrm{~K} /$ Akt.

In the search for small molecule activators of caspase3 , investigators identified a small molecule with proapoptotic effects mediated by a family of proteins named putative HLA-DR-associated proteins (PHAP). ${ }^{44}$ Studies into the mechanism by which this pro-apoptotic agent functions demonstrated that recombinant PHAPI did not affect the efficiency of apoptosome formation, but did promote caspase-9 activation. ${ }^{44}$ The precise molecular mechanism through which the PHAP proteins promote caspase activation is unclear at this time. However, this pro-apoptotic role for PHAPs is consistent with work demonstrating a tumor suppressor role for the proteins. Overexpression of PHAPs has been shown to inhibit transformation of cell lines by known oncogenes, while inhibition of PHAPs causes development of tumorigenic cellular characteristics such as loss of contact inhibition and development of serum-independent growth. ${ }^{61,62}$

\section{Cancer relevance}

\section{Apoptosome defects contributing to tumorigenesis}

Cancer arises due to a disruption in the balance between cell growth and cell death. Defects in the execution of cell death may arise due to alterations in the regulation of apoptosis. The loss of pro-apoptotic signals in response to appropriate stimuli can contribute to aberrant cell growth. Additionally, the overexpression of antiapoptotic signals can prevent cell death in situations that would normally result in the activation of the apoptotic cascade. Defects within the intrinsic pathway have been shown to be important in the pathogenesis of a number of human malignancies, with these alterations arising at a variety of possible steps within the pathway (Table 1).

Disruption of the balance between pro-apoptotic and anti-apoptotic stimuli in human cancers can be attributed to alterations in the expression of Bcl-2 family members that have opposing functions. The pro-survival $\mathrm{Bcl}-$ 2 subfamily members are likely oncogenic, while the pro-apoptotic Bax and Bak proteins may function as

Table 1. Intrinsic pathway defects in human cancers. Studies have demonstrated alterations in the intrinsic pathway of apoptosis at all steps in the pathway, from cytochrome $c$ release to apoptosome formation to caspase activation. Shown here are the pathway step, the defect, and the tumor type in which the results were obtained. These data represent work in primary tumors. Findings in cancer cell lines are discussed in the text but not listed here

\begin{tabular}{|c|c|c|c|}
\hline Intrinsic pathway step & Specific defect & Tumor type & Reference \\
\hline \multirow[t]{6}{*}{ Cytochrome $c$ release } & Bcl-2 overexpression & Follicular lymphoma & {$[107]$} \\
\hline & $\mathrm{Bcl}-\mathrm{x}_{\mathrm{L}}$ overexpression & $\begin{array}{l}\text { Breast, pancreatic, ovarian, colorectal, } \\
\text { esophageal squamous cell carcinomas }\end{array}$ & {$[66-71]$} \\
\hline & Bax or Bak loss-of- & Colon cancer & [73] \\
\hline & function mutations & Gastric and colorectal cancers & {$[75,76]$} \\
\hline & & Hematopoietic malignancies & {$[74]$} \\
\hline & $\begin{array}{l}\text { Akt overexpression } \\
\quad \text { (phosphorylation of Bad) }\end{array}$ & $\begin{array}{l}\text { Breast, ovarian, pancreatic, prostate, } \\
\text { thyroid cancers }\end{array}$ & [94-98] \\
\hline \multirow[t]{8}{*}{ Apoptosome formation } & Decreased or absent & Ovarian cancer & {$[82,83]$} \\
\hline & Apaf- 1 activity & Melanoma & {$[77]$} \\
\hline & & Leukemia & {$[81]$} \\
\hline & Hsp overexpression & $\begin{array}{l}\text { Breast, gastric, endometrial, lung, and } \\
\text { hematopoietic cancers }\end{array}$ & [84] \\
\hline & & Lung cancer & {$[88]$} \\
\hline & & Breast cancer & [45] \\
\hline & ProT overexpression & Colon cancer & {$[90]$} \\
\hline & & Hepatocellular carcinoma & [89] \\
\hline \multirow[t]{6}{*}{ Caspase activation } & $\begin{array}{l}\text { Akt overexpression } \\
\text { (phosphorylation of } \\
\text { procaspase-9) }\end{array}$ & $\begin{array}{l}\text { Breast, ovarian, pancreatic, prostate, } \\
\text { thyroid cancers }\end{array}$ & [93-97] \\
\hline & Survivin overexpression & $\begin{array}{l}\text { Lung, colon, pancreas, prostate, and } \\
\text { breast carcinomas, high-grade } \\
\text { lymphoma, melanoma }\end{array}$ & {$[99,146]$} \\
\hline & & Melanoma & {$[146,147]$} \\
\hline & XIAP overexpression & Acute myelogenous leukemia & {$[103]$} \\
\hline & ML-IAP overexpression & Melanoma & {$[104,105]$} \\
\hline & Loss of PHAPI & Prostate cancer & [62] \\
\hline
\end{tabular}


tumor suppressors. Bcl-2 was first shown to be overexpressed in human cancer when it was identified as part of a translocation involving the immunoglobulin locus in follicular lymphoma. ${ }^{63}$ A causative role for Bcl-2 in cellular transformation was then demonstrated with a transgenic mouse model in which animals overexpressing Bcl-2 develop primitive lymphoid tumors. ${ }^{64} \mathrm{Bcl}-2$ overexpression has now been demonstrated in many human malignancies, including hematopoietic cancers, breast cancer, prostate cancer, and follicular lymphoma. ${ }^{65}$ The Bcl-2 homolog, Bcl- $\mathrm{x}_{\mathrm{L}}$, is overexpressed in breast, pancreatic, colorectal, and esophageal squamous cell carcinomas. ${ }^{66-71}$ The pro-apoptotic Bak subfamily members also appear to be important in human cancers, where they function as tumor suppressors. Bax was first shown to function as a tumor suppressor in transgenic mouse brain tumor model. ${ }^{72}$ Studies have demonstrated loss-of-function mutations in Bax and related protein Bak in gastric, colorectal, and hematopoietic malignancies. ${ }^{73-76}$ Finally, it is likely that $\mathrm{BH} 3$-only proteins may function as tumor suppressor proteins as well based on their ability to promote apoptosis.

Following cytochrome $c$ release, the next step in the intrinsic pathway of apoptosis is apoptosome formation. Defects in apoptosome proteins themselves, such as Apaf1 , have been implicated in human malignancies. The first report of Apaf-1 inactivation in human cancer was the demonstration that malignant melanomas fail to express this protein. ${ }^{77}$ Loss of heterozygosity at the Apaf-1 gene locus was demonstrated at a high rate and the second allele was shown to be inactivated via methylation. ${ }^{77}$ Additional studies have shown that the frequency of Apaf1 loss is higher in metastatic melanomas than primary melanomas, ${ }^{78,79}$ and loss of Apaf- 1 in melanomas is correlated with a poorer patient prognosis. ${ }^{79}$ The finding that both Apaf-1 alleles are inactivated supports the hypothesis that Apaf-1 functions as a tumor suppressor in malignant melanoma. Apaf-1 loss has been reported in additional tumor types including glioblastomas, ${ }^{80}$ leukemia cell lines, ${ }^{81}$ and ovarian cancer. ${ }^{82,83}$ In ovarian cancer cell lines, Apaf- 1 is still expressed but there is decreased functional activity of the protein. ${ }^{82}$ This finding in ovarian cancer cell lines has been validated and also extended to human ovarian cancer tumor specimens. ${ }^{83}$ This impairment of apoptosome function is not due to suppression by known inhibitors, ${ }^{83}$ suggesting the possibility of the presence of a novel protein that modulates Apaf-1 function.

Alterations in the expression of proteins that regulate apoptosome formation have also been proposed to play a role in carcinogenesis, including overexpression of HSPs and ProT. As discussed previously, HSP overexpression functions to inhibit apoptosome formation and apoptosis, thus these proteins may be oncogenic. Many studies have demonstrated an upregulation of HSP expression in human tumors, including breast, gastric, endometrial, lung, and hematopoietic malignancies. ${ }^{84}$ The overexpression of HSPs has been shown to be correlated with poorer clinical outcomes. For example, expression of Hsp70 in breast cancer is correlated with a shorter disease-free survival interval and an increased frequency of metastasis. ${ }^{85,86} \mathrm{HSP}$ overexpression in breast cancer patients also correlates with a decreased responsiveness to induction chemotherapy. ${ }^{86} \mathrm{Clinical}$ and prognostic findings similar to these for Hsp70 have been reported for other HSPs. ${ }^{84}$ In support of a causative role for the overexpression of HSPs in cancer, many cancer cell lines demonstrate an increased level of expression of $\mathrm{Hsp} 70$ and resistance to apoptosis, and some studies report that decreasing levels of Hsp70 in these lines can promote apoptosis. ${ }^{87}$

ProT has been shown to suppress apoptosome formation, ${ }^{44}$ and this may explain the known oncogenic properties of this protein. In vitro studies have demonstrated that ProT is capable of inducing cellular transformation of rodent fibroblasts. ${ }^{46}$ Multiple studies have demonstrated increased expression of ProT in human malignancies compared to normal tissue controls, in cancer types including lung, ${ }^{88}$ hepatocellular, ${ }^{89}$ breast, ${ }^{45}$ and colon. ${ }^{90}$ In lung and breast cancers, the overexpression of ProT has been correlated with a poorer patient prognosis. ${ }^{45,88}$ Such findings are complicated, however, by data suggesting that ProT may be a c-myc target gene, ${ }^{91,92}$ in which case such correlations may reflect elevated expression of the c-myc oncogene in those tumor types, without ProT overexpression necessarily contributing to cellular transformation. With the new finding that ProT suppresses apoptosome formation, one can now postulate that it is through the inhibition of apoptosis that this protein independently serves as an oncoprotein both in vitro and also potentially in vivo.

As discussed previously, the kinase Akt functions to regulate the intrinsic pathway of apoptosis at multiple levels, including inhibiting cytochrome $c$ release by phosphorylating Bad and phosphorylating procaspase-9 to block its activation. Akt lies downstream of PI3K in a cell survival cascade that is activated in response to multiple growth factors. ${ }^{93}$ Many studies have demonstrated that constitutive expression of enzymatically-active Akt results in the inhibition of apoptosis in response to agents that normally trigger the intrinsic pathway, and dominant-negative Akt prevents growth factor-mediated cell survival signaling. ${ }^{93}$ It is plausible that the oncogenic properties of signaling molecules lying upstream of Akt are mediated, at least in part, by the anti-apoptotic effects of Akt on the intrinsic pathway. Upregulation of Akt has been demonstrated in many human tumors, including breast, ovarian, pancreatic, prostate, and thyroid carcinomas. ${ }^{94-98}$ 
Alterations in other proteins that regulate caspase activation, such as IAPs, Smac/DIABLO, HtrA2/Omi, and PHAP may also contribute to cancer development and progression. Of the IAP proteins identified in humans, Survivin appears to have the most clinically relevant link to cancer. This protein has been shown to be overexpressed in cancers but not in normal tissue nor surrounding stroma. ${ }^{99}$ Additionally, in in vitro studies, decreasing Survivin levels has been shown to cause apoptosis and an increased sensitivity to chemotherapeutic agents. ${ }^{100}$ Survivin overexpression has also been correlated with poorer prognosis in a wide variety of tumor types. ${ }^{45}$ It should be noted, however, that Survivin appears to function in the mitotic machinery ${ }^{101}$ and its function in inhibiting apoptosis is still disputed. ${ }^{102}$ Another IAP, XIAP, has been shown to be overexpressed in acute myelogenous leukemia. ${ }^{103}$ Finally, the IAP ML-IAP is overexpressed in melanoma. ${ }^{104,105}$

With regard to the recently identified tumor suppressor PHAPI, the loss of normal PHAP expression has been demonstrated in prostate adenocarcinoma. ${ }^{62}$ The tumor suppressor function of this family of proteins has been demonstrated by a number of independent groups who show that PHAPs are able to inhibit transformation of cell lines by known oncogenes. ${ }^{61,62}$ Thus the modulation of caspase activation, either through inhibition or activation, can affect cellular growth properties and potentially contribute to tumorigenesis.

\section{Intrinsic pathway defects contribute to cancer treatment resistance}

Cancer therapies can exploit the normal cell death pathways to kill cells. Indeed, the common cancer treatment modalities of chemotherapy and radiation therapy primarily cause mitochondrial disruption and activation of the intrinsic pathway of apoptosis to trigger cell death. The intrinsic pathway defects discussed above may contribute to carcinogenesis, and may also serve as mechanisms of resistance to standard cancer therapies. ${ }^{106}$ Correlations between intrinsic pathway defects and altered patient outcomes found in clinical studies are likely secondary to poorer patient response to treatments due to impaired functioning of the cell death pathway. Additionally, many studies performed with cancer cell lines have demonstrated at a molecular level that defects in the molecules required for execution of the intrinsic pathway of apoptosis account for resistance to therapeutic agents.

Research suggests that alterations in Bcl-2 expression contribute to drug resistance observed in cancer cells. These data include clinical studies showing a correlation between high levels of Bcl-2 expression and poor clinical outcomes ${ }^{107,108}$ and experiments demonstrating that overexpression of $\mathrm{Bcl}-2$ can result in drug resistance in cancer cell lines. ${ }^{109}$ Similar findings have been reported for the $\mathrm{Bcl}-2$ homolog $\mathrm{Bcl}-\mathrm{x}_{\mathrm{L}}$, suggesting that its overexpression may also contribute to resistance to cancer treatments. ${ }^{66-71,106}$ The role of alterations in the proapoptotic Bak and $\mathrm{BH} 3$-only subfamilies remains to be more fully investigated.

One example of the role of intrinsic pathway defects in treatment resistance is the finding that alterations in Apaf1 expression or function result in drug resistance. Apaf-1 deficiency accounts for defective stress-induced apoptosis in human leukemia cell lines and a cervical cancer cell line, with the reintroduction of Apaf-1 into these cells resulting in restoration of apoptosis. ${ }^{81,110}$ In ovarian cancer cell lines, defective Apaf-1 function is correlated with chemoresistance. ${ }^{82,83}$ In a human prostate cancer cell line, an alternatively spliced form of Apaf- 1 is expressed and the cells demonstrate impaired apoptosis, but reintroduction of full-length Apaf-1 restores the apoptotic pathway. ${ }^{111}$ These studies are important in demonstrating a causative role for Apaf-1 defects in therapy resistance, based on the ability of the cell death pathway and drug sensitivity to be restored following reintroduction of Apaf-1.

At the level of caspase activation within the intrinsic pathway there are also potential defects that contribute to drug resistance within cancer cells. A number of studies have implicated activated Akt in the chemoresistant phenotype of tumor cells. Akt modulates cisplatin resistance in ovarian cancer cells, with expression of active Akt causing chemoresistance and expression of dominant-negative Akt resulting in sensitivity to standard chemotherapeutic agents. ${ }^{112-114}$ Similar findings have also been reported in breast cancer cell lines. ${ }^{115}$ In ovarian cancer cell lines resistant to chemotherapeutic agents, down-regulating XIAP can induce cellular apoptosis. ${ }^{116}$ This suggests that the overexpression of XIAP in these lines in contributies to chemoresistance. In addition, overexpression of XIAP and other IAPs, including NIAP, cIAP1, and cIAP2, has been reported to result in decreased sensitivity to chemotherapeutic agents in vitro. ${ }^{117}$ The ability of XIAP overexpression to confer chemoresistance to tumor cells may be in part due to XIAP up-regulating the PI3K/Akt pathway, resulting in phosphorylation and activation of Akt, which then can exert its anti-apoptotic effects. ${ }^{113,118}$

\section{Targeting intrinsic pathway defects for therapeutic intervention}

As cancer treatment approaches move toward targeting the specific molecular aberrations present in tumor cells, the intrinsic pathway of apoptosis is an excellent site for such targeted therapies. ${ }^{119}$ Targeted therapeutics focused upon defects in the intrinsic pathway have two potential mechanisms of facilitating cell death in cancer cells. 
The first is to restore the normal apoptotic pathway so that cells regain sensitivity to standard chemotherapeutic agents. Such an approach has been illustrated above in considering apoptosome defects in human cancers, with multiple groups showing that reintroduction of a protein required for apoptosome function restores chemosensitivity. Another mechanism to induce cell death in cells with defects in the intrinsic pathway is to trigger and drive apoptosis in the absence of additional signals. This approach has been most strongly exploited in attempts to disrupt Bcl-2 function in cancer cells, but other specific molecules are being targeted as well.

Overexpression of the anti-apoptotic family members $\mathrm{Bcl}-2$ and $\mathrm{Bcl}-\mathrm{x}_{\mathrm{L}}$ is proposed to occur in over half of all human cancers, ${ }^{120}$ and multiple techniques are being used to decrease expression of these proteins in the attempt to alter tumor growth. One approach has been to use antisense nucleotides, such as an oligonucleotide complementary to the first 18 nucleotides of the Bcl-2 coding sequence called G3139. This antisense nucleotide has been shown to result in downregulation of $\mathrm{Bcl}-2$ and improved patient outcomes, ${ }^{121}$ leading to the initiation of additional clinical studies on the molecule. For example, phase III randomized clinical trials with $\mathrm{Bcl}-2$ antisense oligonucleotides are ongoing in patients with solid breast tumors. ${ }^{122}$ Gene therapy approaches are also being developed to disrupt Bcl-2 function in cancer cells. Adenovirus expressing $\mathrm{Bcl}-\mathrm{xs}$, a splice variant of $\mathrm{Bcl}-\mathrm{x}$ that acts as a dominant negative repressor of $\mathrm{Bcl}-2$ and $\mathrm{Bcl}-\mathrm{x}_{\mathrm{L}}$, is able to induce apoptosis of breast cancer cells in a mouse model ${ }^{123}$ and a clinical trial using the $\mathrm{Bcl}-\mathrm{xs}$ adenovirus is currently underway. ${ }^{124}$ A number of additional approaches are being investigated to interfere with $\mathrm{Bcl}-2$ function in tumor cells, including the use of peptide analogs of $\mathrm{BH} 3$-only proteins $^{125}$ and the design of small molecule inhibitors of Bcl-2. ${ }^{119,126}$

In addition to targeting Bcl-2, other proteins important in the intrinsic pathway of apoptosis are being targeted to treat cancer cells. Given the central location of the PI3K/Akt pathway downstream in many growth factor signaling cascades and its dysregulation in human cancers, Akt represents an excellent target for molecular therapeutics. ${ }^{127}$ One Akt small molecule inhibitor, perifosine, is currently in phase II clinical trials for the treatment of a number of solid tumor malignancies. ${ }^{128,129}$ Additional small molecule inhibitors of Akt are being investigated, including phosphatidylinositol analogs that block Akt activation ${ }^{130,131}$ and the natural plant product deguelin, ${ }^{132}$ although the specificity of such compounds for Akt remains to be more clearly demonstrated.

Another approach that has been investigated by a number of groups is to release the endogenous suppression of caspases by IAPs, so that the caspases can then trigger cell death. A number of endogenous IAP inhibitors have been identified, including Smac/DIABLO and Omi/HtrA2. Two groups have reported the introduction of Smac peptides into tumor cells to inhibit IAPs and therefore allow caspase activation. ${ }^{133,134}$ Interestingly, in both of these reports the Smac peptide was not sufficient to result in cell killing, but did provide chemosensitization so that tumor cells responded to conventional chemotherapy. ${ }^{133,134}$ In a similar approach to block IAP suppression of caspases, a recent paper reports the identification of eight polyphenylurea compounds that function as small molecule inhibitors of XIAP, with testing of the compound 1396-34 in multiple cell culture and animal tumor models. ${ }^{135}$ Of note, this polyphenylurea compound releases XIAP suppression of an effector caspase, caspase3 , resulting in direct cell killing without the need for adjuvant chemotherapy. ${ }^{135}$ This suggests that caspase- 3 is already active in tumor cells, with its apoptotic effects being held in-check by XIAP, ${ }^{136}$ a hypothesis supported by the finding that processed caspase- 3 is present in tumor cells. ${ }^{137}$ It is proposed that the differential requirement for adjuvant chemotherapy with Smac mimetics as compared to the XIAP small molecule inhibitor is based on the different site to which the two compounds bind on XIAP, with Smac peptides only releasing caspase-9 inhibition, and the XIAP small molecule inhibitor releasing caspase- 3 inhibition. ${ }^{136}$ Additional approaches to block IAP suppression of caspases are also being explored, including the use of antisense oligonucleotides to XIAP. ${ }^{119}$ Inhibition of the IAP Survivin has been carried out using antisense and dominant-negative constructs expressed either on plasmids or adenoviral vectors. ${ }^{138-140}$

\section{Discussion}

The molecular players in the intrinsic pathway of apoptosis are becoming increasingly well-characterized, forming a picture of an intricately regulated pathway for type I programmed cell death. The intrinsic pathway can be considered to occur in three major steps, the release of cytochrome $c$ from mitochondria, apoptosome formation with initiator caspase activation, and effector caspase activation and execution of the cell death program. As outlined above, each of these steps is regulated by multiple proteins that themselves are subject to regulation. Defects in pathway proteins or their regulators may contribute to both tumorigenesis and drug resistance, and may represent novel targets for molecular therapeutics.

Both expression studies in primary tumors and mechanistic studies in the cell culture setting suggest that deregulation of the intrinsic pathway of apoptosis is important in cancer development and progression. However, the question remains as to whether the intrinsic pathway is truly essential in carrying out stress-induced cell death, or whether the pathway merely functions to amplify the apoptotic signal. ${ }^{141,142}$ In both $C$. elegans and 
D. melanogaster, apoptosis takes place in a mitochondriaindependent manner. ${ }^{142}$ Gene knock-out studies in mice have also raised the question as to the essential nature of the intrinsic pathway, with aspects of the data both supporting and arguing against the necessity of the mitochondrial pathway. Apaf-1 and caspase- 9 knock-out mice fail to undergo normal neuronal cell death and demonstrate resistance to some methods of stress-induced apoptosis, suggesting that these proteins are necessary for apoptosis. However, the animals continue to demonstrate intact apoptotic mechanisms in some aspects of their development. ${ }^{143}$ In independent work using cells deficient for both Apaf-1 and caspase-9, it was demonstrated that cells can still undergo stress-induced apoptosis, and importantly $\mathrm{Bcl}-2$ overexpression functions to protect these cells from programmed cell death. ${ }^{144}$ This suggests that $\mathrm{Bcl}-2$ can act in a cytochrome $c$ and apoptosomeindependent manner to protect cells, perhaps via a sequestration model in which $\mathrm{Bcl}-2$ binds a CED- 4 homolog other than Apaf-1, analogous to apoptosis regulation in C. elegans. ${ }^{142}$

These findings, in combination with the previously discussed data supporting cross-talk between the extrinsic and intrinsic pathways of apoptosis, argue that perhaps the intrinsic pathway functions to amplify the apoptotic signal rather than as a mechanism by which caspase activation is initiated. ${ }^{141,142}$ How does one reconcile the data for and against an essential role for the mitochondrial pathway? There are a number of possible explanations, primarily founded on the great complexity of the human system. Likely there are yet unidentified proteins that regulate apoptosis, including both caspases and also potentially a CED-4 homolog other than Apaf- 1 that serves as a scaffold protein for caspase activation. It is also likely that there is tissue specificity with regard to the proteins expressed and pathways exploited in apoptosis, an argument easily supported by the observation that Apaf- 1 and caspase-9 knock-out mice demonstrate intact cell death pathways in some but not all tissues. ${ }^{143}$ Finally, there may be redundancy in function among apoptotic proteins, providing safety mechanisms for the cells and also making delineation of the pathways more challenging.

The question as to the essential nature of the intrinsic pathway of apoptosis has implications for understanding the role of the pathway in human cancer development and tumor resistance. Arguably, if the intrinsic pathway is not essential then intrinsic pathway defects may not result in impaired cell death contributing to tumorigenesis, as other apoptotic mechanisms remain intact. On the other hand, even if the mitochondrial pathway is merely a mechanism by which the death signal is amplified, it still may be necessary to obtain the level of cell death required to maintain tissue homeostasis. As reviewed above, there is mounting data supporting a role for apoptosome defects in human cancer, both based on expression studies in tumors and mechanistic studies in tissue culture systems. Increasing evidence suggests that perhaps there are non-apoptotic cell death mechanisms important in tissue homeostasis that are altered in human cancer, including the degradative pathway of autophagy. ${ }^{145}$ The prevailing viewpoint at this time is that standard cancer treatments, including chemotherapy and radiation therapy, trigger the intrinsic pathway of apoptosis. If tumors demonstrate resistance to these conventional treatment modalities, it may be possible to restore the intrinsic pathway or bypass the defect. Alternatively, defects in the intrinsic pathway might signal the need for a broader approach to treatment, such as activating the extrinsic pathway of apoptosis, or other types of cell death such as autophagy or necrosis. Future work will need to not only clarify the role of the intrinsic pathway of apoptosis in human cancer and therapeutic drug resistance, but also address the interplay between apoptotic and non-apoptotic mechanisms of cell death in malignancy and its treatment.

\section{Acknowledgments}

We thank Marisol Soengas for careful review of the manuscript.

\section{References}

1. Raff M. Cell suicide for beginners. Nature 1998; 396: 119122.

2. Ameisen JC. On the origin, evolution, and nature of programmed cell death: A timeline of four billion years. Cell Death Differ 2002; 9: 367-393.

3. Budihardjo I, Oliver H, Lutter M, Luo X, Wang X. Biochemical pathways of caspase activation during apoptosis. Anпu Rev Cell Dev Biol 1999; 15: 269-290.

4. Ashkenazi A, Dixit VM. Death receptors: Signaling and modulation. Science 1998; 281: 1305-1308.

5. Liu X, Kim CN, Yang J, Jemmerson R, Wang X. Induction of apoptotic program in cell-free extracts: Requirement for dATP and cytochrome $c$. Cell 1996; 86: 147-157.

6. Li P, Nijhawan D, Budihardjo I, et al. Cytochrome $c$ and dATP-dependent formation of Apaf-1/caspase- 9 complex initiates an apoptotic protease cascade. Cell 1997; 91: 479489.

7. Zou H, Henzel WJ, Liu X, Lutschg A, Wang X. Apaf-1, a human protein homologous to $C$. elegans CED-4, participates in cytochrome $c$-dependent activation of caspase-3. Cell 1997; 90: 405-413.

8. Benedict MA, Hu Y, Inohara N, Nunez G. Expression and functional analysis of Apaf-1 isoforms. Extra WD-40 repeat is required for cytochrome $c$ binding and regulated activation of procaspase-9.J Biol Chem 2000; 275: 8461-8468.

9. Acehan D, Jiang X, Morgan DG, Heuser JE, Wang X, Akey CW. Three-dimensional structure of the apoptosome: Implications for assembly, procaspase-9 binding, and activation. Mol Cell 2002; 9: 423-432.

10. Jiang X, Wang X. Cytochrome C-Mediated Apoptosis. Annu Rev Biochem 2004; 73: 87-106.

11. Srinivasula SM, Ahmad M, Fernandes-Alnemri T, Alnemri ES. Autoactivation of procaspase- 9 by Apaf-1-mediated oligomerization. Mol Cell 1998; 1: 949-957. 
12. Shi Y. Mechanisms of caspase activation and inhibition during apoptosis. Mol Cell 2002; 9: 459-470.

13. Thornberry NA, Lazebnik Y. Caspases: Enemies within. Science 1998; 281: 1312-1316.

14. Li H, Zhu H, Xu CJ, Yuan J. Cleavage of BID by caspase 8 mediates the mitochondrial damage in the Fas pathway of apoptosis. Cell 1998; 94: 491-501.

15. Lassus $\mathrm{P}$, Opitz-Araya X, Lazebnik Y. Requirement for caspase-2 in stress-induced apoptosis before mitochondrial permeabilization. Science 2002; 297: 1352-1354.

16. Kumar S, Vaux DL. Apoptosis. A cinderella caspase takes center stage. Science 2002; 297: 1290-1291.

17. McDonnell MA, Wang D, Khan SM, Vander Heiden MG, Kelekar A. Caspase-9 is activated in a cytochrome $c$ independent manner early during TNFalpha-induced apoptosis in murine cells. Cell Death Differ 2003; 10: 1005-1015.

18. Cory S, Adams JM. The Bcl2 family: Regulators of the cellular life-or-death switch. Nat Rev Cancer 2002; 2: 647-656.

19. Janiak F, Leber B, Andrews DW. Assembly of Bcl-2 into microsomal and outer mitochondrial membranes. J Biol Chem 1994; 269: 9842-9849.

20. Kluck RM, Bossy-Wetzel E, Green DR, Newmeyer DD. The release of cytochrome $c$ from mitochondria: A primary site for Bcl-2 regulation of apoptosis. Science 1997; 275: 1132-1136.

21. Yang J, Liu X, Bhalla K, et al. Prevention of apoptosis by Bcl-2: Release of cytochrome $c$ from mitochondria blocked. Science 1997; 275: 1129-1132.

22. Moriishi K, Huang DC, Cory S, Adams JM. Bcl-2 family members do not inhibit apoptosis by binding the caspase activator Apaf-1. Proc Natl Acad Sci USA 1999; 96: 96839688.

23. Gross A, McDonnell JM, Korsmeyer SJ. BCL-2 family members and the mitochondria in apoptosis. Genes Dev 1999; 13: 1899-1911.

24. Antonsson B, Conti F, Ciavatta A, et al. Inhibition of Bax channel-forming activity by Bcl-2. Science 1997; 277: 370372.

25. Antonsson B, Montessuit S, Lauper S, Eskes R, Martinou JC. Bax oligomerization is required for channel-forming activity in liposomes and to trigger cytochrome $c$ release from mitochondria. Biochem J 2000; 345: 271-278.

26. Saito M, Korsmeyer SJ, Schlesinger PH. BAX-dependent transport of cytochrome $c$ reconstituted in pure liposomes. Nat Cell Biol 2000; 2: 553-555.

27. Cheng EH, Wei MC, Weiler S, et al. BCL-2, BCL-X(L) sequester $\mathrm{BH} 3$ domain-only molecules preventing $\mathrm{BAX}$ - and BAK-mediated mitochondrial apoptosis. Mol Cell 2001; 8: 705-711.

28. Zong WX, Lindsten T, Ross AJ, MacGregor GR, Thompson $\mathrm{CB}$. BH3-only proteins that bind pro-survival Bcl-2 family members fail to induce apoptosis in the absence of Bax and Bak. Genes Dev 2001; 15: 1481-1486.

29. Lindsten T, Ross AJ, King A, et al. The combined functions of proapoptotic Bcl-2 family members bak and bax are essential for normal development of multiple tissues. Mol Cell 2000; 6: 1389-1399.

30. Datta SR, Dudek H, Tao X, et al. Akt phosphorylation of BAD couples survival signals to the cell-intrinsic death machinery. Cell 1997; 91: 231-241.

31. del Peso L, Gonzalez-Garcia M, Page C, Herrera R, Nunez G. Interleukin-3-induced phosphorylation of BAD through the protein kinase Akt. Science 1997; 278: 687-689.

32. Danial NN, Gramm CF, Scorrano L, et al. BAD and glucokinase reside in a mitochondrial complex that integrates glycolysis and apoptosis. Nature 2003; 424: 952-956.
33. Ferguson HA, Marietta PM, Van Den Berg CL. UV-induced apoptosis is mediated independent of caspase-9 in MCF-7 cells: A model for cytochrome $c$ resistance. J Biol Chem 2003; 278: 45793-45800.

34. Beere HM, Green DR. Stress management-heat shock protein-70 and the regulation of apoptosis. Trends Cell Biol 2001; 11: 6-10.

35. Beere HM, Wolf BB, Cain K, et al. Heat-shock protein 70 inhibits apoptosis by preventing recruitment of procaspase- 9 to the Apaf-1 apoptosome. Nat Cell Biol 2000; 2: 469-475.

36. Saleh A, Srinivasula SM, Balkir L, Robbins PD, Alnemri ES. Negative regulation of the Apaf-1 apoptosome by Hsp70. Nat Cell Biol 2000; 2: 476-483.

37. Ravagnan L, Gurbuxani S, Susin SA, et al. Heat-shock protein 70 antagonizes apoptosis-inducing factor. Nat Cell Biol 2001; 3: 839-843.

38. Susin SA, Lorenzo HK, Zamzami N, et al. Molecular characterization of mitochondrial apoptosis-inducing factor. Nature 1999; 397: 441-446.

39. Pandey P, Saleh A, Nakazawa A, et al. Negative regulation of cytochrome $c$-mediated oligomerization of Apaf- 1 and activation of procaspase-9 by heat shock protein 90. Embo J 2000; 19: 4310-4322.

40. Bruey JM, Ducasse C, Bonniaud P, et al. Hsp27 negatively regulates cell death by interacting with cytochrome c. Nat Cell Biol 2000; 2: 645-652.

41. Concannon CG, Orrenius S, Samali A. Hsp27 inhibits cytochrome $c$-mediated caspase activation by sequestering both pro-caspase-3 and cytochrome c. Gene Expr 2001; 9: 195-201.

42. Hughes FM, Jr., Bortner CD, Purdy GD, Cidlowski JA. Intracellular $\mathrm{K}+$ suppresses the activation of apoptosis in lymphocytes. J Biol Chem 1997; 272: 30567-30576.

43. Cain K, Langlais C, Sun XM, Brown DG, Cohen GM. Physiological concentrations of $\mathrm{K}+$ inhibit cytochrome $c$ dependent formation of the apoptosome. J Biol Chem 2001; 276: 41985-41990.

44. Jiang X, Kim HE, Shu H, et al. Distinctive roles of PHAP proteins and prothymosin-alpha in a death regulatory pathway. Science 2003; 299: 223-226.

45. Magdalena C, Dominguez F, Loidi L, Puente JL. Tumour prothymosin alpha content, a potential prognostic marker for primary breast cancer. Br J Cancer 2000; 82: 584-590.

46. Orre RS, Cotter MA, 2nd, Subramanian C, Robertson ES Prothymosin alpha functions as a cellular oncoprotein by inducing transformation of rodent fibroblasts in vitro. $J$ Biol Chem 2001; 276: 1794-1799.

47. Deveraux QL, Roy N, Stennicke HR, et al. IAPs block apoptotic events induced by caspase- 8 and cytochrome $c$ by direct inhibition of distinct caspases. Embo J 1998; 17: 2215-2223.

48. Deveraux QL, Leo E, Stennicke HR, Welsh K, Salvesen GS Reed JC. Cleavage of human inhibitor of apoptosis protein XIAP results in fragments with distinct specificities for caspases. Embo J 1999; 18: 5242-5251.

49. Deveraux QL, Reed JC. IAP family proteins-suppressors of apoptosis. Genes Dev 1999; 13: 239-252.

50. Deveraux QL, Takahashi R, Salvesen GS, Reed JC. X-linked IAP is a direct inhibitor of cell-death proteases. Nature 1997; 388: 300-304.

51. Roy N, Deveraux QL, Takahashi R, Salvesen GS, Reed JC. The $c$-IAP-1 and $c$-IAP-2 proteins are direct inhibitors of specific caspases. Embo J 1997; 16: 6914-6925.

52. Du C, Fang M, Li Y, Li L, Wang X. Smac, a mitochondrial protein that promotes cytochrome $c$-dependent caspase activation by eliminating IAP inhibition. Cell 2000; 102: 33-42. 
53. Verhagen AM, Ekert PG, Pakusch M, et al. Identification of DIABLO, a mammalian protein that promotes apoptosis by binding to and antagonizing IAP proteins. Cell 2000; 102: 43-53.

54. Suzuki Y, Imai Y, Nakayama H, Takahashi K, Takio K, Takahashi R. A serine protease, HtrA2, is released from the mitochondria and interacts with XIAP, inducing cell death. Mol Cell 2001; 8: 613-621.

55. Hegde R, Srinivasula SM, Zhang Z, et al. Identification of Omi/HtrA2 as a mitochondrial apoptotic serine protease that disrupts inhibitor of apoptosis protein-caspase interaction. $J$ Biol Chem 2002; 277: 432-438.

56. Martins LM, Iaccarino I, Tenev T, et al. The serine protease Omi/HtrA2 regulates apoptosis by binding XIAP through a reaper-like motif. J Biol Chem 2002; 277: 439-444.

57. van Loo G, van Gurp M, Depuydt B, et al. The serine protease $\mathrm{Omi} / \mathrm{HtrA} 2$ is released from mitochondria during apoptosis. Omi interacts with caspase-inhibitor XIAP and induces enhanced caspase activity. Cell Death Differ 2002; 9: 2026.

58. Verhagen AM, Silke J, Ekert PG, et al. HtrA2 promotes cell death through its serine protease activity and its ability to antagonize inhibitor of apoptosis proteins. J Biol Chem 2002; 277: 445-454.

59. Suzuki Y, Takahashi-Niki K, Akagi T, Hashikawa T, Takahashi R. Mitochondrial protease Omi/HtrA2 enhances caspase activation through multiple pathways. Cell Death Differ 2004; 11: 208-216.

60. Cardone MH, Roy N, Stennicke HR, et al. Regulation of cell death protease caspase-9 by phosphorylation. Science 1998; 282: 1318-1321.

61. Chen TH, Brody JR, Romantsev FE, et al. Structure of pp32, an acidic nuclear protein which inhibits oncogene-induced formation of transformed foci. Mol Biol Cell 1996; 7: 20452056.

62. Bai J, Brody JR, Kadkol SS, Pasternack GR. Tumor suppression and potentiation by manipulation of pp32 expression. Oncogene 2001; 20: 2153-2160.

63. Tsujimoto Y, Finger LR, Yunis J, Nowell PC, Croce CM. Cloning of the chromosome breakpoint of neoplastic B cells with the $\mathrm{t}(14 ; 18)$ chromosome translocation. Science 1984; 226: 1097-1099.

64. Strasser A, Harris AW, Bath ML, Cory S. Novel primitive lymphoid tumours induced in transgenic mice by cooperation between myc and bcl-2. Nature 1990; 348: 331-333.

65. Reed JC, Miyashita T, Takayama S, et al. BCL-2 family proteins: Regulators of cell death involved in the pathogenesis of cancer and resistance to therapy. J Cell Biochem 1996; 60: $23-32$.

66. Olopade OI, Adeyanju MO, Safa AR, et al. Overexpression of BCL-x protein in primary breast cancer is associated with high tumor grade and nodal metastases. Cancer J Sci Am 1997; 3: $230-237$.

67. Friess H, Lu Z, Andren-Sandberg A, et al. Moderate activation of the apoptosis inhibitor bcl-xL worsens the prognosis in pancreatic cancer. Ann Surg 1998; 228: 780-787.

68. Marone M, Scambia G, Mozzetti S, et al. bcl-2, bax, bcl$\mathrm{XL}$, and bcl-XS expression in normal and neoplastic ovarian tissues. Clin Cancer Res 1998; 4: 517-524.

69. Biroccio A, Benassi B, D’Agnano I, et al. $c$-Myb and Bcl-x overexpression predicts poor prognosis in colorectal cancer: Clinical and experimental findings. Am J Pathol 2001; 158: 1289-1299.

70. Rubio N, Espana L, Fernandez Y, Blanco J, Sierra A. Metastatic behavior of human breast carcinomas overexpress- ing the $\mathrm{Bcl}-\mathrm{x}(\mathrm{L})$ gene: A role in dormancy and organospecificity. Lab Invest 2001; 81: 725-734.

71. Takayama T, Nagao M, Sawada H, et al. Bcl-X expression in esophageal squamous cell carcinoma: Association with tumor progression and prognosis. J Surg Oncol 2001; 78: 116-123.

72. Yin C, Knudson CM, Korsmeyer SJ, Van Dyke T. Bax suppresses tumorigenesis and stimulates apoptosis in vivo. Nature 1997; 385: 637-640.

73. Rampino N, Yamamoto H, Ionov $Y$, et al. Somatic frameshift mutations in the BAX gene in colon cancers of the microsatellite mutator phenotype. Science 1997; 275: 967-969.

74. Meijerink JP, Mensink EJ, Wang K, et al. Hematopoietic malignancies demonstrate loss-of-function mutations of BAX. Blood 1998; 91: 2991-2997.

75. Ionov Y, Yamamoto H, Krajewski S, Reed JC, Perucho M. Mutational inactivation of the proapoptotic gene BAX confers selective advantage during tumor clonal evolution. Proc Natl Acad Sci USA 2000; 97: 10872-10877.

76. Kondo S, Shinomura Y, Miyazaki Y, et al. Mutations of the bak gene in human gastric and colorectal cancers. Cancer Res 2000; 60: 4328-4330.

77. Soengas MS, Capodieci P, Polsky D, et al. Inactivation of the apoptosis effector Apaf-1 in malignant melanoma. Nature 2001; 409: 207-211.

78. Baldi A, Santini D, Russo P, et al. Analysis of APAF-1 expression in human cutaneous melanoma progression. Exp Dermatol 2004; 13: 93-97.

79. Fujimoto A, Takeuchi H, Taback B, et al. Allelic imbalance of 12q22-23 associated with APAF-1 locus correlates with poor disease outcome in cutaneous melanoma. Cancer Res 2004; 64: 2245-2250.

80. Watanabe T, Hirota Y, Arakawa Y, et al. Frequent LOH at chromosome 12q22-23 and Apaf-1 inactivation in glioblastoma. Brain Pathol 2003; 13: 431-439.

81. Jia L, Srinivasula SM, Liu FT, et al. Apaf-1 protein deficiency confers resistance to cytochrome $c$-dependent apoptosis in human leukemic cells. Blood 2001; 98: 414-421.

82. Wolf BB, Schuler M, Li W, et al. Defective cytochrome $c$ dependent caspase activation in ovarian cancer cell lines due to diminished or absent apoptotic protease activating factor-1 activity. J Biol Chem 2001; 276: 34244-34251.

83. Liu JR, Opipari AW, Tan L, et al. Dysfunctional apoptosome activation in ovarian cancer: Implications for chemoresistance. Cancer Res 2002; 62: 924-931.

84. Jolly C, Morimoto RI. Role of the heat shock response and molecular chaperones in oncogenesis and cell death. $J$ Natl Cancer Inst 2000; 92: 1564-1572.

85. Ciocca DR, Clark GM, Tandon AK, Fuqua SA, Welch WJ, McGuire WL. Heat shock protein hsp70 in patients with axillary lymph node-negative breast cancer: Prognostic implications. J Natl Cancer Inst 1993; 85: 570574.

86. Vargas-Roig LM, Gago FE, Tello O, Aznar JC, Ciocca DR. Heat shock protein expression and drug resistance in breast cancer patients treated with induction chemotherapy. Int $J$ Cancer 1998; 79: 468-475.

87. Wei YQ, Zhao X, Kariya Y, Teshigawara K, Uchida A. Inhibition of proliferation and induction of apoptosis by abrogation of heat-shock protein (HSP) 70 expression in tumor cells. Cancer Immunol Immunother 1995; 40: 73-78.

88. Sasaki H, Nonaka M, Fujii Y, et al. Expression of the prothymosin-a gene as a prognostic factor in lung cancer. Surg Today 2001; 31: 936-938.

89. Wu CG, Habib NA, Mitry RR, Reitsma PH, van Deventer SJ, Chamuleau RA. Overexpression of hepatic prothymosin 
alpha, a novel marker for human hepatocellular carcinoma. $\mathrm{Br}$ J Cancer 1997; 76: 1199-1204.

90. Mori M, Barnard GF, Staniunas RJ, Jessup JM, Steele GD, Jr., Chen LB. Prothymosin-alpha mRNA expression correlates with that of $c$-myc in human colon cancer. Oncogene 1993; 8: 2821-2826.

91. Gaubatz S, Meichle A, Eilers M. An E-box element localized in the first intron mediates regulation of the prothymosin alpha gene by $c$-myc. Mol Cell Biol 1994; 14: 3853-3862.

92. Desbarats L, Gaubatz S, Eilers M. Discrimination between different E-box-binding proteins at an endogenous target gene of $c$-myc. Genes Dev 1996; 10: 447-460.

93. Datta SR, Brunet A, Greenberg ME. Cellular survival: A play in three Akts. Genes Dev 1999; 13: 2905-2927.

94. Bellacosa A, de Feo D, Godwin AK, et al. Molecular alterations of the AKT2 oncogene in ovarian and breast carcinomas. Int $J$ Cancer 1995; 64: 280-285.

95. Ringel MD, Hayre N, Saito J, et al. Overexpression and overactivation of Akt in thyroid carcinoma. Cancer Res 2001; 61: 6105-6111.

96. Sun M, Wang G, Paciga JE, et al. AKT1/PKBalpha kinase is frequently elevated in human cancers and its constitutive activation is required for oncogenic transformation in NIH3T3 cells. Am J Pathol 2001; 159: 431-437.

97. Schlieman MG, Fahy BN, Ramsamooj R, Beckett L, Bold RJ. Incidence, mechanism and prognostic value of activated AKT in pancreas cancer. Br J Cancer 2003; 89: 2110-2115.

98. Stal O, Perez-Tenorio G, Akerberg L, et al. Akt kinases in breast cancer and the results of adjuvant therapy. Breast Cancer Res 2003; 5: R37-44.

99. Ambrosini G, Adida C, Altieri DC. A novel anti-apoptosis gene, survivin, expressed in cancer and lymphoma. Nat Med 1997; 3: 917-921.

100. Ambrosini G, Adida C, Sirugo G, Altieri DC. Induction of apoptosis and inhibition of cell proliferation by survivin gene targeting. J Biol Chem 1998; 273: 11177-11182.

101. Adams RR, Carmena M, Earnshaw WC. Chromosomal passengers and the (aurora) ABCs of mitosis. Trends Cell Biol 2001; 11: 49-54.

102. Banks DP, Plescia J, Altieri DC, et al. Survivin does not inhibit caspase-3 activity. Blood 2000; 96: 4002-4003.

103. Tamm I, Kornblau SM, Segall H, et al. Expression and prognostic significance of IAP-family genes in human cancers and myeloid leukemias. Clin Cancer Res 2000; 6: 1796-1803.

104. Vucic D, Stennicke HR, Pisabarro MT, Salvesen GS, Dixit VM. ML-IAP, a novel inhibitor of apoptosis that is preferentially expressed in human melanomas. Curr Biol 2000; 10: $1359-1366$.

105. Kasof GM, Gomes BC. Livin, a novel inhibitor of apoptosis protein family member. J Biol Chem 2001; 276: 3238-3246.

106. Kaufmann SH, Vaux DL. Alterations in the apoptotic machinery and their potential role in anticancer drug resistance. Oncogene 2003; 22: 7414-7430.

107. Reed JC. Regulation of apoptosis by bcl-2 family proteins and its role in cancer and chemoresistance. Curr Opin Oncol 1995; 7: 541-546.

108. Reed JC. Dysregulation of apoptosis in cancer. J Clin Oncol 1999; 17: 2941-2953

109. Miyashita T, Reed JC. bcl-2 gene transfer increases relative resistance of S49.1 and WEHI7.2 lymphoid cells to cell death and DNA fragmentation induced by glucocorticoids and multiple chemotherapeutic drugs. Cancer Res 1992; 52: $5407-$ 5411.

110. Kamarajan P, Sun NK, Sun CL, Chao CC. Apaf-1 overexpression partially overcomes apoptotic resistance in a cisplatin-selected HeLa cell line. FEBS Lett 2001; 505: 206 212.

111. Ogawa T, Shiga K, Hashimoto S, Kobayashi T, Horii A, Furukawa T. APAF-1-ALT, a novel alternative splicing form of APAF-1, potentially causes impeded ability of undergoing DNA damage-induced apoptosis in the LNCaP human prostate cancer cell line. Biochem Biophys Res Commun 2003; 306: 537-543.

112. Page C, Lin HJ, Jin $\mathrm{Y}$, et al. Overexpression of Akt/AKT can modulate chemotherapy-induced apoptosis. Anticancer Res 2000; 20: 407-416.

113. Fraser M, Leung BM, Yan X, Dan HC, Cheng JQ, Tsang BK. p53 is a determinant of X-linked inhibitor of apoptosis protein/Akt-mediated chemoresistance in human ovarian cancer cells. Cancer Res 2003; 63: 7081-7088.

114. Yuan ZQ, Feldman RI, Sussman GE, Coppola D, Nicosia SV, Cheng JQ. AKT2 inhibition of cisplatin-induced JNK/p38 and Bax activation by phosphorylation of ASK1: Implication of AKT2 in chemoresistance. J Biol Chem 2003; 278: 23432 23440 .

115. Knuefermann C, Lu Y, Liu B, et al. HER2/PI-3K/Akt activation leads to a multidrug resistance in human breast adenocarcinoma cells. Oncogene 2003; 22: 3205-3212.

116. Sasaki H, Sheng Y, Kotsuji F, Tsang BK. Down-regulation of $\mathrm{X}$-linked inhibitor of apoptosis protein induces apoptosis in chemoresistant human ovarian cancer cells. Cancer Res 2000; 60: 5659-5666.

117. Liston P, Roy N, Tamai K, et al. Suppression of apoptosis in mammalian cells by NAIP and a related family of IAP genes. Nature 1996; 379: 349-353.

118. Asselin E, Mills GB, Tsang BK. XIAP regulates Akt activity and caspase-3-dependent cleavage during cisplatin-induced apoptosis in human ovarian epithelial cancer cells. Cancer Res 2001; 61: 1862-1868.

119. Reed JC. Apoptosis-targeted therapies for cancer. Cancer Cell 2003; 3: 17-22.

120. Amundson SA, Myers TG, Scudiero D, Kitada S, Reed JC, Fornace AJ, Jr. An informatics approach identifying markers of chemosensitivity in human cancer cell lines. Cancer Res 2000; 60: 6101-6110.

121. Cotter FE. Antisense therapy of hematologic malignancies. Semin Hematol 1999; 36: 9-14.

122. Nahta R, Esteva FJ. Bcl-2 antisense oligonucleotides: A potential novel strategy for the treatment of breast cancer. Semin Oncol 2003; 30: 143-149.

123. Ealovega MW, McGinnis PK, Sumantran VN, Clarke MF, Wicha MS. bcl-xs gene therapy induces apoptosis of human mammary tumors in nude mice. Cancer Res 1996; 56: 1965 1969.

124. Ayash LJ, Clarke M, Adams P, et al. Clinical protocol. Purging of autologous stem cell sources with bcl-x(s) adenovirus for women undergoing high-dose chemotherapy for stage IV breast carcinoma. Hum Gene Ther 2001; 12: 2023-2025.

125. Letai A, Bassik MC, Walensky LD, Sorcinelli MD, Weiler S, Korsmeyer SJ. Distinct BH3 domains either sensitize or activate mitochondrial apoptosis, serving as prototype cancer therapeutics. Cancer Cell 2002; 2: 183-192.

126. Enyedy IJ, Ling Y, Nacro K, et al. Discovery of small-molecule inhibitors of Bcl-2 through structure-based computer screening. J Med Chem 2001; 44: 4313-4324.

127. Luo J, Manning BD, Cantley LC. Targeting the PI3K-Akt pathway in human cancer: Rationale and promise. Cancer Cell 2003; 4: 257-262.

128. Kondapaka SB, Singh SS, Dasmahapatra GP, Sausville EA, Roy KK. Perifosine, a novel alkylphospholipid, inhibits 
protein kinase B activation. Mol Cancer Ther 2003; 2: $1093-$ 1103.

129. De Siervi A, Marinissen M, Diggs J, Wang XF, Pages G, Senderowicz A. Transcriptional activation of $\mathrm{p} 21$ (waf1/cip1) by alkylphospholipids: Role of the mitogen-activated protein kinase pathway in the transactivation of the human p21(waf1/cip1) promoter by Sp1. Cancer Res 2004; 64: 743750.

130. Hu Y, Qiao L, Wang S, et al. 3-(Hydroxymethyl)-bearing phosphatidylinositol ether lipid analogues and carbonate surrogates block PI3-K, Akt, and cancer cell growth.J Med Chem 2000; 43: 3045-3051.

131. Kozikowski AP, Sun H, Brognard J, Dennis PA. Novel PI analogues selectively block activation of the pro-survival serine/threonine kinase Akt. J Am Chem Soc 2003; 125: $1144-$ 1145 .

132. Chun KH, Kosmeder JW, 2nd, Sun S, et al. Effects of deguelin on the phosphatidylinositol 3-kinase/Akt pathway and apoptosis in premalignant human bronchial epithelial cells. $J$ Natl Cancer Inst 2003; 95: 291-302.

133. Fulda S, Wick W, Weller M, Debatin KM. Smac agonists sensitize for Apo2L/TRAIL- or anticancer drug-induced apoptosis and induce regression of malignant glioma in vivo. Nat Med 2002; 8: 808-815.

134. Yang L, Mashima T, Sato S, et al. Predominant suppression of apoptosome by inhibitor of apoptosis protein in non-small cell lung cancer H460 cells: Therapeutic effect of a novel polyarginine-conjugated Smac peptide. Cancer Res 2003; 63: 831-837.

135. Schimmer AD, Welsh K, Pinilla C, et al. Small-molecule antagonists of apoptosis suppressor XIAP exhibit broad antitumor activity. Cancer Cell 2004; 5: 25-35.

136. Huang Y, Lu M, Wu H. Antagonizing XIAP-mediated caspase-3 inhibition. Achilles' heel of cancers? Cancer Cell 2004; 5: 1-2

137. Yang L, Cao Z, Yan H, Wood WC. Coexistence of high levels of apoptotic signaling and inhibitor of apoptosis proteins in human tumor cells: Implication for cancer specific therapy. Cancer Res 2003; 63: 6815-6824.

138. Blanc-Brude OP, Mesri M, Wall NR, Plescia J, Dohi T, Altieri DC. Therapeutic targeting of the survivin pathway in cancer: Initiation of mitochondrial apoptosis and suppression of tumor-associated angiogenesis. Clin Cancer Res 2003; 9: 2683-2692.

139. Pisarev V, Yu B, Salup R, Sherman S, Altieri DC, Gabrilovich DI. Full-length dominant-negative survivin for cancer immunotherapy. Clin Cancer Res 2003; 9: 6523-6533.

140. Tu SP, Jiang XH, Lin MC, et al. Suppression of survivin expression inhibits in vivo tumorigenicity and angiogenesis in gastric cancer. Cancer Res 2003; 63: 7724-7732.

141. Finkel E. The mitochondrion: Is it central to apoptosis? Science 2001; 292: 624-626.

142. Baliga B, Kumar S. Apaf-1/cytochrome $c$ apoptosome: An essential initiator of caspase activation or just a sideshow? Cell Death Differ 2003; 10: 16-18.

143. Zheng TS, Hunot S, Kuida K, Flavell RA. Caspase knockouts: Matters of life and death. Cell Death Differ 1999; 6: $1043-$ 1053.

144. Marsden VS, O'Connor L, O'Reilly LA, et al. Apoptosis initiated by Bcl-2-regulated caspase activation independently of the cytochrome c/Apaf-1/caspase-9 apoptosome. Nature 2002; 419: 634-637.

145. Ogier-Denis E, Codogno P. Autophagy: A barrier or an adaptive response to cancer. Biochim Biophys Acta 2003; 1603: 113128.

146. Grossman D, McNiff JM, Li F, Altieri DC. Expression and targeting of the apoptosis inhibitor, survivin, in human melanoma. J Invest Dermatol 1999; 113: 1076-1081.

147. Chiodino C, Cesinaro AM, Ottani D, et al. Communication: Expression of the novel inhibitor of apoptosis survivin in normal and neoplastic skin. J Invest Dermatol 1999; 113: 415418. 